\title{
Differential Regulation of Protein Synthesis and mTOR Signaling in Skeletal Muscle and Visceral Tissues of Neonatal Pigs After a Meal
}

\author{
MARÍA C. GAZZANEO, RENÁN A. ORELLANA, AGUS SURYAWAN, ALEXANDER P. TUCKOW, SCOT R. KIMBALL, \\ FIONA A. WILSON, HANH V. NGUYEN, ROBERTO M. TORRAZZA, MARTA L. FIOROTTO, AND TERESA A. DAVIS \\ Department of Pediatrics [M.C.G., R.A.O., A.S., F.A.W., H.V.N., R.M.T., M.L.F., T.A.D.], United States Department of \\ Agriculture/Agriculture Research Service, Children's Nutrition Research Center, Baylor College of Medicine, Houston, Texas 77030; \\ Department of Cellular \& Molecular Physiology [A.P.T., S.R.K.], Pennsylvania State University College of Medicine, Hershey, \\ Pennsylvania 17033
}

\begin{abstract}
Protein synthesis (PS) increases after a meal in neonates, but the time course of the changes in PS in different tissues after a meal is unknown. We aimed to evaluate the changes in tissue PS, mammalian target of rapamycin complex 1 (mTORC1) activation, and proportion of ribosomal protein (rp) mRNAs in polysomes over $4 \mathrm{~h}$ after a bolus meal in neonatal pigs ( $n=6$ /group; 5 - to 7-d-old). The results show a more sustained increase in PS in glycolytic compared with mixed fiber type muscles and no changes in oxidative muscles. PS increased in liver, jejunum, and pancreas but not in kidney and heart. Feeding did not affect AMP-activated protein kinase or RAS-related GTP binding B activation. Phosphorylation of tuberous sclerosis complex 2, prolinerich Akt substrate of $40 \mathrm{kD}$, mTOR, eukaryotic initiation factor $4 \mathrm{E}$ binding protein, and rp S6 kinase 1 increased in all tissues after feeding. The proportion of mRNAs encoding rp S4 and S8 in liver polysomes increased within $30 \mathrm{~min}$ postfeeding. These results suggest that feeding stimulates mTORC1 signaling in muscle and viscera, but mTORC1 activation alone is not sufficient to stimulate PS in all tissues. (Pediatr Res 70: 253-260, 2011)
\end{abstract}

$\mathrm{T}$ The neonatal period is characterized by rapid growth and deposition of body protein $(1,2)$. Despite these features, $10 \%$ of newborn babies in the United States are of LBW $(3,4)$. These infants have a higher incidence of subnormal postnatal growth and neurodevelopmental problems $(5,6)$. Elucidating the mechanisms that regulate protein accretion in infants may facilitate the improvement of the nutritional management and overall outcome of this population.

Using the neonatal pig as a model of the human infant, we have shown that feeding stimulates protein synthesis (PS) in skeletal muscle (7-9), and this effect is modulated independently by the rise in insulin and amino acids (AA) $(10,11)$. This postprandial increase in insulin and AA enhances PS in muscles that contain primarily fast-twitch glycolytic fibers because of the activation of mammalian target of rapamycin complex 1 (mTORC1) signaling proteins that activate the mRNA binding step in translation initiation (12-14). mTORC1 activation in-

Received January 12, 2011; accepted March 29, 2011

Correspondence: Teresa A. Davis, Ph.D., Department of Pediatrics, USDA/ARS Children's Nutrition Research Center, Baylor College of Medicine, 1100 Bates Street, Houston, TX 77030; e-mail: tdavis@bcm.edu

Supported, in part, by the National Institutes of Health grants R01 AR-44474, R01 DK15658, and K08 AR-51563 and the USDA/ARS under Cooperative Agreement number 6250510000-33. volves the phosphorylation of proline-rich Akt substrate of 40 $\mathrm{kD}$ (PRAS40), resulting in 70-kDa ribosomal protein (rp) S6 kinase (S6K1) and eukaryotic initiation factor (eIF) 4E binding protein-1 (4EBP1) activation (15). The binding between Ras related GTP binding protein (Rag) A-D and mTORC1 seems important for mTORC1 activation (16). An increase in AMP levels and subsequent activation of AMP-activated protein kinase (AMPK) leads to activation of tuberous sclerosis complex 2 (TSC2) and inhibition of mTOR (17). It has yet to be determined whether muscles with different fiber types respond similarly in the neonate.

Feeding also stimulates PS in visceral tissues of the neonate, including the liver (7). We have shown that this response to feeding is mediated by the rise in AA, but not insulin, after a meal $(10,18)$. PS stimulation in the liver involves an increase in translation initiation, but the effect in other visceral tissues of the neonate is not known.

Most studies that have investigated the effect of feeding have done so at one time point, and little is known about the temporal changes in PS and mTORC1 signaling in various tissues after a meal. Recently, we demonstrated that feeding stimulates PS rapidly in fast-twitch glycolytic muscle of the neonate but returns to baseline by $4 \mathrm{~h}$ after a meal (19). This response is mirrored by the activation of the mTORC1 signaling pathway. The present study was performed to compare the time course of the changes in PS rates and mTORC1 activation in skeletal muscles of different fiber types and in visceral tissues after a meal.

\section{MATERIALS AND METHODS}

Animals. Sows and piglets were housed and managed as previously described (20). Piglets remained with the sow after birth and were not given supplemental creep feed. Piglets were studied at 5 to $7 \mathrm{~d}$ of age $(1.77 \pm 0.07$ $\mathrm{kg}$ ). Three days before infusion, piglets underwent surgery for jugular vein

Abbreviations: AA, amino acids; AMPK, AMP-activated protein kinase; BCAA, branched-chain AA; EAA, essential AA; 4EBP1, eukaryotic initiation factor 4E binding protein 1; GAPDH, glyceraldehyde 3-phosphate dehydrogenase; mTORC1, mammalian target of rapamycin complex 1; ODC, ornithine decarboxylase; PRAS40, proline-rich Akt substrate of $40 \mathrm{kDa}$; PS, protein synthesis; Rag, Ras-related GTP binding protein; rp, ribosomal protein; S6K1, rp S6 kinase 1; TAA, total AA; TSC2, tuberous sclerosis complex 2 
and carotid artery catheter placement (7). Piglets were returned to their sows until the day of study. The protocol (19) was approved by the Animal Care and Use Committee of Baylor College of Medicine and was conducted in accordance with the National Research Council's Guide for the Care and Use of Laboratory Animals.

Treatments and infusions. Overnight fasted piglets were randomly assigned to one of six treatment groups ( $n=6 /$ treatment): 1$)$ food deprived, 2$)$ fed $30 \mathrm{~min}, 3$ ) fed $60 \mathrm{~min}$, 4) fed $90 \mathrm{~min}, 5$ ) fed $120 \mathrm{~min}$, and 6) fed $240 \mathrm{~min}$ as previously described (19). Briefly, piglets were killed after overnight fasting ( $0 \mathrm{~min}$ ) or were assigned to a fed group and enterally fed with a bolus meal delivered over a 15 -min period $(40 \mathrm{~mL} / \mathrm{kg}$ body wt) of Soweena Litter Life replacement for sow's milk (Merricks, Inc., Middleton, WI). Fed pigs were killed at $30,60,90,120$, or 240 min after the meal. Blood samples were collected every $15 \mathrm{~min}$ and immediately analyzed for branched-chain AA concentration (BCAA) by a rapid enzymatic kinetic assay (21) and glucose using a YSI 2300 STAT Plus (Yellow Spring Instruments, Yellow Spring, $\mathrm{OH})$. Plasma samples were collected and frozen every $15 \mathrm{~min}$ for the first $2 \mathrm{~h}$ and every $30 \mathrm{~min}$ for the remaining $2 \mathrm{~h}$ for insulin analysis by a porcine insulin RIA kit (Linco, St. Louis, MO) and AA by HPLC (PICO-TAG reverse-phase column, Waters, Milford, MA) (8).

Tissue PS in vivo. The fractional rate of PS was measured with a flooding dose of L- $\left[4-{ }^{3} \mathrm{H}\right]$ phenylalanine (7). For all groups, except the 30-min fed group, piglets received L-[4- $\left.{ }^{3} \mathrm{H}\right]$ phenylalanine $(1.5 \mathrm{mmol} / \mathrm{kg}$ body wt, 0.5 $\mathrm{mCi} / \mathrm{kg}$ body wt; American Radiolabeled Chemicals, Inc., St. Louis, MO) injected $30 \mathrm{~min}$ before the end of the infusion. For piglets in the 30-min fed group, $\mathrm{L}-\left[4-{ }^{3} \mathrm{H}\right]$ phenylalanine $(1.5 \mathrm{mmol} / \mathrm{kg}$ body wt, $1.0 \mathrm{mCi} / \mathrm{kg}$ body $\mathrm{wt})$ was injected 15 min before infusion end. Piglets were killed, and samples from the gastrocnemius, masseter, soleus, left heart, liver, pancreas, jejunum, and kidney were obtained, immediately frozen in liquid nitrogen, and stored at $-70^{\circ} \mathrm{C}$ until analyzed as previously described (7).

Protein immunoblot analysis. Equal amounts of protein from tissue homogenates (100-150 mg tissue in 700-1050 mL homogenizing buffer) were separated by SDS PAGE. For each assay, all samples were run at the same time on triple-wide gels (C.B.S. Scientific, Del Mar, CA) to reduce interassay variation. Proteins were electrophoretically transferred to polyvinylidene difluoride transfer membranes (Pall Corporation, Pensacola, FL), which were blocked and then incubated with appropriate primary antibodies in dilution 1:1000: AMPK (total and Thr ${ }^{172}$; Cell Signaling Technology, Inc., Danvers, MA); TSC2 (total; Santa Cruz Biotechnology, Inc., Santa Cruz, CA; and $\mathrm{Thr}^{1462}$; Cell Signaling Technology, Inc.); RagB (Abcam, Inc., Cambridge, MA); mTOR (total and $\mathrm{Ser}^{2448}$, Cell Signaling Technology, Inc.); PRAS40 (total and Thr ${ }^{246}$; Cell Signaling Technology, Inc.); 4EBP1 (total, Bethyl Laboratories, Inc., Montgomery, TX; and $\mathrm{Thr}^{70}$; Cell Signaling Technology, Inc.); and S6K1 (total and Thr ${ }^{398}$; Cell Signaling Technology, Inc.), and after washing were exposed to an appropriate secondary antibody (1:5000-10000 dilution; Bio-Rad, Hercules, CA) as previously described (22). Blots were visualized and analyzed using a ChemiDoc-It Imaging System (UVP, Upland, CA). Phosphorylation values were normalized by protein abundance in the samples.

Table 1. Primers for GAPDH, ODC, rpS4, and rpS8

\begin{tabular}{|c|c|}
\hline GAPDH forward & 5'-ACTCACTCTTCTACCTTTGATGCT-3' \\
\hline GAPDH reverse & 5'-TGTTGCTGTAGCCAAATTCA-3' \\
\hline ODC forward & 5'-CACCTGTTCACTGCGAGTTT-3' \\
\hline ODC reverse & 5'-TGTGACCCATCTCCTTGTCT-3' \\
\hline rpS4 forward & 5'-GTACCATCCGCTACCCTGAT-3' \\
\hline rpS4 reverse & 5'-CAGGTTAGCACCTCCAGTCA-3' \\
\hline rpS8 forward & $5^{\prime}$-CTAGAGGAGCAGTTCCAGCA-3' \\
\hline
\end{tabular}

Analysis of protein-protein interaction. To determine the association between RagB and mTOR, tissue samples were homogenized in 3[(3Cholamidopropyl) dimethylammonio]-propanesulfonic acid (CHAPS) buffer and immunoprecipitated as previously described (22).

Reverse transcription and real-time quantitative PCR. The proportion of rp S4 (rpS4), S8 (rpS8), and ornithine decarboxylase (ODC) mRNAs in the polysomal fraction of sucrose density gradients was determined in the liver. After sucrose density centrifugation, RNA was isolated from the subpolysomal and polysomal fractions of the gradient via the Trizol method, and an equal quantity ( $1 \mu \mathrm{g}$ RNA) from each fraction was reverse transcribed to cDNA using the SuperScript First-Strand Synthesis System for RT-PCR (Invitrogen, Carlsbad, CA). The resulting cDNA was used to quantify the relative abundance of $\mathrm{rp}$ in the polysomal fraction using glyceraldehyde 3-phosphate dehydrogenase (GAPDH) for normalization. Assays were performed using QuantiTect SYBR Green real time PCR master mix (Qiagen, Valencia, CA) and reactions performed and analyzed on an ABI 7900HT Fast Real-Time PCR System (Applied Biosystems, Carlsbad, CA). For primer sets used for qRT-PCR, see Table 1. qRT-PCR results were quantitated using a relative standard curve generated for each primer set via 4-fold serial dilutions (1:1-1:256) of one of the cDNA samples. A 1:16 dilution of cDNA was used for all other samples. The relative expression values were obtained via SDS 2.2.2 software (Applied Biosystems).

Calculations and statistics. The fractional rate of PS $(K \mathrm{~s}$, percentage of protein mass synthesized in a day) was calculated as previously described (23). Statistical analysis was carried out in SPSS (Version 17.0). A protected post hoc LSD $t$ test was used to determine statistical differences between groups if, after performing a one-way ANOVA, we found a statistical significance $(p<0.05)$. Analysis of glucose and insulin across time was carried out with SPSS General Linear Model Repeated Measures Test for within-subject effects. Probability values of $<0.05$ were considered significant, and data are presented as means \pm SEM.

\section{RESULTS}

Substrates and hormones. Circulating hormone and substrate concentrations during a 4-h period after meal ingestion were reported previously and are presented here for reference (19). Glucose increased 2-fold above fasting levels after a bolus meal and peaked around 60 min postfeeding (Table 2; $p<0.001)$. By 240 min postprandially, glucose levels decreased but not to baseline $(p=0.016)$. Insulin concentrations increased postfeeding, reached maximum levels by $60 \mathrm{~min}$ (Table 2; $p<0.001$ ) and declined but not to baseline after 240 $\min (p=0.004)$. BCAA levels increased about 2 -fold above baseline values $30 \mathrm{~min}$ after a meal (Table $2 ; p<0.001$ ) and returned to baseline by $240 \mathrm{~min}$. Nonessential AA concentrations did not change significantly but essential AA (EAA) and total AA (TAA) levels mirrored those of the BCAA, increasing at $30 \mathrm{~min}(p<0.05)$ and remaining elevated through at least 120 min postfeeding $(p<0.05)$.

Protein synthesis. PS in gastrocnemius and masseter muscles increased 30 min postfeeding (Fig. $1 A$ and $B ; p<0.05$ ), remained elevated for $90 \mathrm{~min}$ in the gastrocnemius $(p<$

Table 2. Circulating AA, insulin, and glucose concentrations in response to feeding*

\begin{tabular}{|c|c|c|c|c|c|c|c|}
\hline & \multicolumn{6}{|c|}{ Time (min) } & \multirow[b]{2}{*}{$p$} \\
\hline & 0 & 30 & 60 & 90 & 120 & 240 & \\
\hline $\mathrm{EAA}(\mathrm{nmol} / \mathrm{mL})$ & $1010 \pm 5.2 \dagger$ & $1404 \pm 6.8 \div$ & $1422 \pm 7.8 \ddagger$ & $1357 \pm 8.1 \div$ & $1437 \pm 12.8 \ddagger$ & $1012 \pm 11.5 \dagger$ & $<0.05$ \\
\hline NEAA $(\mathrm{nmol} / \mathrm{mL})$ & $2028 \pm 8.1$ & $2124 \pm 11.1$ & $2234 \pm 14$ & $2266 \pm 16.1$ & $2179 \pm 27.1$ & $1815 \pm 18.0$ & NS \\
\hline $\mathrm{BCAA}(\mathrm{nmol} / \mathrm{mL})$ & $451 \pm 3.5 \dagger$ & $672 \pm 2.1 \ddagger$ & $682 \pm 3.2 \ddagger$ & $630 \pm 3.0 \neq$ & $702 \pm 3.5 \ddagger$ & $528 \pm 2.6 \dagger$ & $<0.001$ \\
\hline $\mathrm{TAA}(\mathrm{nmol} / \mathrm{mL})$ & $3038 \pm 6.8 \dagger$ & $3528 \pm 9.2 \ddagger$ & $3657 \pm 11.2 \ddagger$ & $3623 \pm 12.5 \$$ & $3616 \pm 20.6 \ddagger$ & $2827 \pm 15.3 \dagger$ & $<0.05$ \\
\hline Insulin $(\mu \mathrm{U} / \mathrm{mL})$ & $8.3 \pm 0.6 \dagger$ & $86.4 \pm 7.1 \ddagger$ & $103.7 \pm 8.0 \S$ & $82.5 \pm 9.9 \neq$ & $57.4 \pm 6.5 \|$ & $16.6 \pm 2.8 \pi$ & $<0.001$ \\
\hline Glucose (mg/dL) & $81 \pm 2.1 \dagger$ & $168 \pm 7.0 \div$ & $206 \pm 10.7 \S$ & $186 \pm 12.1 \neq$ & $175 \pm 10.5 \ddagger$ & $94 \pm 7.2 \ddagger$ & $<0.001$ \\
\hline
\end{tabular}

$*$ Values are means \pm SEM, $n=6-36$. Means in a row with superscripts without a common symbol differ, $p<0.05$. Phenylalanine at 240 min is not included in the calculation of EAA and TAA as the flooding dose of $\left[{ }^{3} \mathrm{H}\right]$ phenylalanine was administered at 210 min and artificially increased levels of EAA and TAA.

NEAA, nonessential AA. 


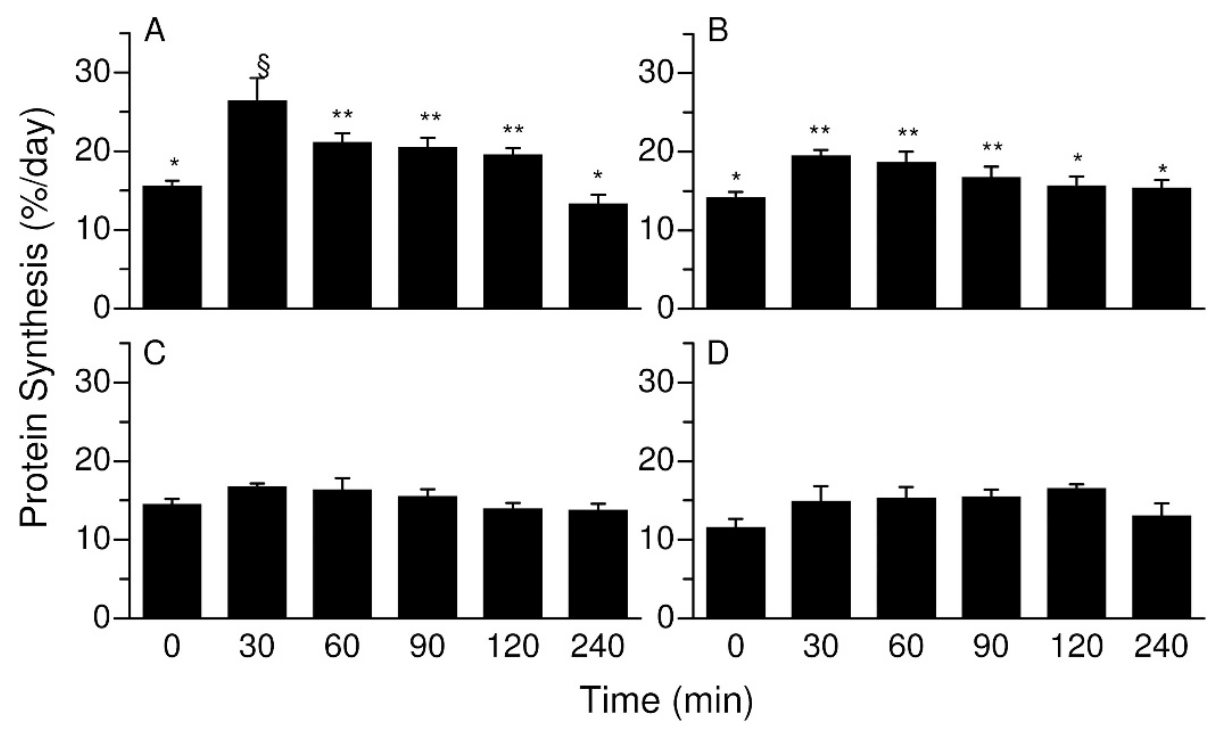

Figure 1. Time course of the changes in PS rates in gastrocnemius $(A)$, masseter $(B)$, soleus $(C)$, and left heart $(D)$ muscles of neonatal pigs after a meal. Values are means \pm SEM, $n=4-6$. ANOVA showed a treatment effect on PS $(p<0.05)$ in gastrocnemius and masseter. Means without a common symbol differ, $p<0.05$.

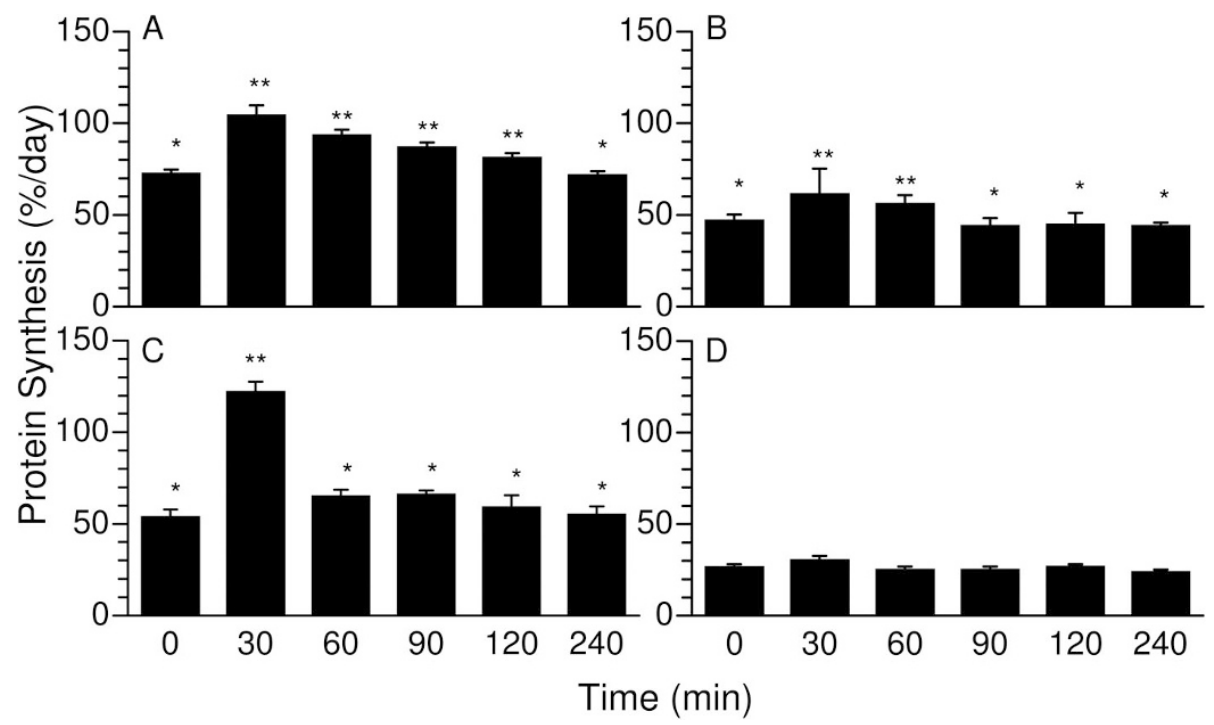

Figure 2. Time course of the changes in PS rates in liver $(A)$, jejunum $(B)$, pancreas $(C)$, and kidney $(D)$ of neonatal after a meal. Values are means \pm SEM, $n=4-6$. ANOVA showed a treatment effect on PS in liver $(p<0.001)$, jejunum $(p<$ $0.05)$, and pancreas $(p<0.05)$. Means without a common symbol differ, $p<0.05$.

$0.007)$ and $60 \mathrm{~min}$ in the masseter $(p<0.009)$, and returned to fasting levels by $120 \mathrm{~min}$ in both muscles. There was no significant increase in PS in the soleus and left heart after feeding (Fig. $1 C$ and $D$ ).

In the liver, PS increased within 30 min after a meal (Fig. $2 A ; p<0.001)$, remained elevated for at least $90 \mathrm{~min}(p<$ 0.04 ) and returned to baseline $120 \mathrm{~min}$ postfeeding. PS increased in the jejunum between 30 and $60 \mathrm{~min}$ (Fig. 2B; $p<0.05$ ) and in the pancreas by 30 min postfeeding (Fig. $2 C ; p<0.05)$. There was no significant effect of feeding on PS in the kidney (Fig. 2D).

mTORC1 activation. AMPK and RagB GTPase phosphorylation in all muscles were unaltered by a bolus meal (Table 3). TSC2 phosphorylation increased 30 min postprandially, was maintained for $120 \mathrm{~min}$ in all muscles, and returned to baseline by 240 min (Table 3; $p<0.05$ ). PRAS40 (Table 3; $p<0.05$ ) and mTOR phosphorylation (Fig. 3; $p<0.05$ ) increased $30 \mathrm{~min}$ after a meal in the gastrocnemius, masseter, soleus, and left heart and returned to baseline by $240 \mathrm{~min}$. 4EBP1 and S6K1 phosphorylation increased $30 \mathrm{~min}$ after a meal in the gastrocnemius, masseter, soleus, and left heart (Table 3; $p<0.01$ ); was maintained for $120 \mathrm{~min}$, and returned to baseline by $240 \mathrm{~min}$.

AMPK and RagB GTPase phosphorylation were not altered by a meal in all visceral tissues (Table 4). However, TSC2 phosphorylation in the liver, jejunum, pancreas, and kidney increased $30 \mathrm{~min}$ postprandially, was maintained for $120 \mathrm{~min}$, and returned to baseline by $240 \mathrm{~min}$ (Table $4 ; p<0.05$ ). PRAS40 (Table $4 ; p<0.05$ ) and mTOR phosphorylation (Fig. 4; $p<0.05$ ) increased 30 min postfeeding in all viscera and returned to baseline by $240 \mathrm{~min}$. 4EBP1 phosphorylation in the liver increased to maximum levels at $30 \mathrm{~min}$ postprandially (Table $4 ; p<0.002$ ) and returned to baseline by 240 min. In the jejunum, pancreas, and kidney (Table $4 ; p<0.01$ ), 4EBP1 phosphorylation increased after feeding with peak levels at $30 \mathrm{~min}$ and remained elevated for $120 \mathrm{~min}$ in the jejunum and pancreas $(p<0.05)$ and for $90 \mathrm{~min}$ in the kidney $(p<0.05)$. S6K1 phosphorylation in all viscera reached maximum levels at $30 \mathrm{~min}$ postfeeding, remained elevated for $90 \mathrm{~min}$ in the liver and kidney (Table $4 ; p<0.05$ ) and for 120 
Table 3. Time course of the changes in the activation of various signaling proteins involved in translation in muscles of neonatal pigs after a meal*

\begin{tabular}{|c|c|c|c|c|c|c|c|}
\hline & \multicolumn{6}{|c|}{ Time (min) } & \multirow[b]{2}{*}{$p$} \\
\hline & 0 & 30 & 60 & 90 & 120 & 240 & \\
\hline \multicolumn{8}{|l|}{ Gastrocnemius } \\
\hline TSC2 on $\mathrm{Thr}^{1462}(\mathrm{AU})$ & $0.10 \pm 0.01 \dagger$ & $1.23 \pm 0.18$ & $1.21 \pm 0.17 \ddagger$ & $0.81 \pm 0.15 \S$ & $0.67 \pm 0.08 \|$ & $0.13 \pm 0.03 \dagger$ & $<0.05$ \\
\hline PRAS40 on $\mathrm{Thr}^{246}(\mathrm{AU})$ & $0.57 \pm 0.9 \dagger$ & $7.76 \pm 0.83$ & $7.58 \pm 1.18 \ddagger$ & $4.25 \pm 0.50 \S$ & $3.02 \pm 0.40 \|$ & $0.75 \pm 0.13 \dagger$ & $<0.05$ \\
\hline RagB-mTOR (AU) & $0.39 \pm 0.07$ & $0.33 \pm 0.05$ & $0.39 \pm 0.05$ & $0.37 \pm 0.04$ & $0.42 \pm 0.07$ & $0.40 \pm 0.06$ & NS \\
\hline S6K1 on $\mathrm{Thr}^{398}$ (AU) & $2.54 \pm 0.44 \dagger$ & $20.35 \pm 4.30 \%$ & $15.65 \pm 3.77 \S$ & $14.31 \pm 3.18 \S$ & $8.49 \pm 1.30 \|$ & $3.86 \pm 0.74 \dagger$ & $<0.05$ \\
\hline \multicolumn{8}{|l|}{ Masseter } \\
\hline AMPK on $\mathrm{Thr}^{172}(\mathrm{AU})$ & $0.66 \pm 0.08$ & $0.76 \pm 0.11$ & $0.66 \pm 0.15$ & $0.77 \pm 0.18$ & $0.73 \pm 0.17$ & $0.64 \pm 0.10$ & NS \\
\hline TSC2 on $\operatorname{Thr}^{1462}(\mathrm{AU})$ & $0.42 \pm 0.05 \dagger$ & $5.80 \pm 0.65$ & $6.04 \pm 0.54 \ddagger$ & $4.83 \pm 0.85 \S$ & $3.13 \pm 0.59 \|$ & $0.75 \pm 0.14 \dagger$ & $<0.05$ \\
\hline PRAS40 on $\mathrm{Thr}^{246}(\mathrm{AU})$ & $0.04 \pm 0.01 \dagger$ & $0.60 \pm 0.08$ & $0.58 \pm 0.08 \ddagger$ & $0.35 \pm 0.02 \|$ & $0.23 \pm 0.03 \|$ & $0.04 \pm 0.01 \dagger$ & $<0.05$ \\
\hline RagB-mTOR (AU) & $0.80 \pm 0.15$ & $0.73 \pm 0.09$ & $0.79 \pm 0.09$ & $0.84 \pm 0.07$ & $0.75 \pm 0.10$ & $0.72 \pm 0.10$ & NS \\
\hline S6K1 on $\mathrm{Thr}^{398}(\mathrm{AU})$ & $0.14 \pm 0.05 \dagger$ & 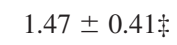 & $1.42 \pm 0.40 \ddagger$ & $0.85 \pm 0.21 \|$ & $0.71 \pm 0.20 \|$ & $0.24 \pm 0.13 \dagger$ & $<0.05$ \\
\hline RagB-mTOR (AU) & $0.64 \pm 0.11$ & $0.63 \pm 0.08$ & $0.55 \pm 0.08$ & $0.67 \pm 0.11$ & $0.59 \pm 0.09$ & $0.68 \pm 0.07$ & NS \\
\hline S6K1 on $\mathrm{Thr}^{398}$ (AU) & $0.10 \pm 0.03 \dagger$ & $2.04 \pm 0.26 \ddagger$ & $1.54 \pm 0.32 \S$ & $1.00 \pm 0.13 \S$ & $0.46 \pm 0.09 \|$ & $0.14 \pm 0.03 \dagger$ & $<0.05$ \\
\hline 4E-BP1 on $\mathrm{Thr}^{70}(\mathrm{AU})$ & $0.11 \pm 0.02 \dagger$ & $2.15 \pm 0.26$ & $1.90 \pm 0.18 \S$ & $1.43 \pm 0.14 \S$ & $0.77 \pm 0.10 \|$ & $0.12 \pm 0.02 \dagger$ & $<0.05$ \\
\hline \multicolumn{8}{|l|}{ Left heart } \\
\hline AMPK on $\mathrm{Thr}^{172}(\mathrm{AU})$ & $0.37 \pm 0.11$ & $0.30 \pm 0.07$ & $0.36 \pm 0.05$ & $0.35 \pm 0.06$ & $0.31 \pm 0.06$ & $0.33 \pm 0.04$ & NS \\
\hline TSC2 on $\mathrm{Thr}^{1462}(\mathrm{AU})$ & $0.05 \pm 0.03 \dagger$ & $0.80 \pm 0.07 \ddagger$ & $0.93 \pm 0.11 \ddagger$ & $0.55 \pm 0.10 \|$ & $0.43 \pm 0.06 \|$ & $0.07 \pm 0.01 \dagger$ & $<0.05$ \\
\hline PRAS40 on $\mathrm{Thr}^{246}$ (AU) & $0.38 \pm 0.05 \dagger$ & $4.65 \pm 0.64$ & $4.35 \pm 0.58 \ddagger$ & $3.00 \pm 0.46 \S$ & $2.03 \pm 0.27 \|$ & $0.45 \pm 0.04 \dagger$ & $<0.05$ \\
\hline RagB-mTOR (AU) & $0.24 \pm 0.03$ & $0.22 \pm 0.02$ & $0.25 \pm 0.01$ & $0.23 \pm 0.03$ & $0.22 \pm 0.02$ & $0.24 \pm 0.03$ & NS \\
\hline S6K1 on $\mathrm{Thr}^{398}(\mathrm{AU})$ & $0.12 \pm 0.04 \dagger$ & $1.90 \pm 0.48$ & $1.41 \pm 0.32 \S$ & $0.91 \pm 0.17 \S$ & $0.62 \pm 0.06 \|$ & $0.12 \pm 0.02 \dagger$ & $<0.05$ \\
\hline 4E-BP1 on $\mathrm{Thr}^{70}$ (AU) & $0.14 \pm 0.03 \dagger$ & $2.49 \pm 0.23 \ddagger$ & $2.02 \pm 0.20 \S$ & $1.56 \pm 0.37 \S$ & $0.94 \pm 0.12 \|$ & $0.14 \pm 0.02 \dagger$ & $<0.05$ \\
\hline
\end{tabular}

* Values are means $\pm \mathrm{SEM}, \mathrm{n}=6$. Means in a row with superscripts without a common symbol differ, $p<0.05$.

$\mathrm{AU}$, arbitrary units.

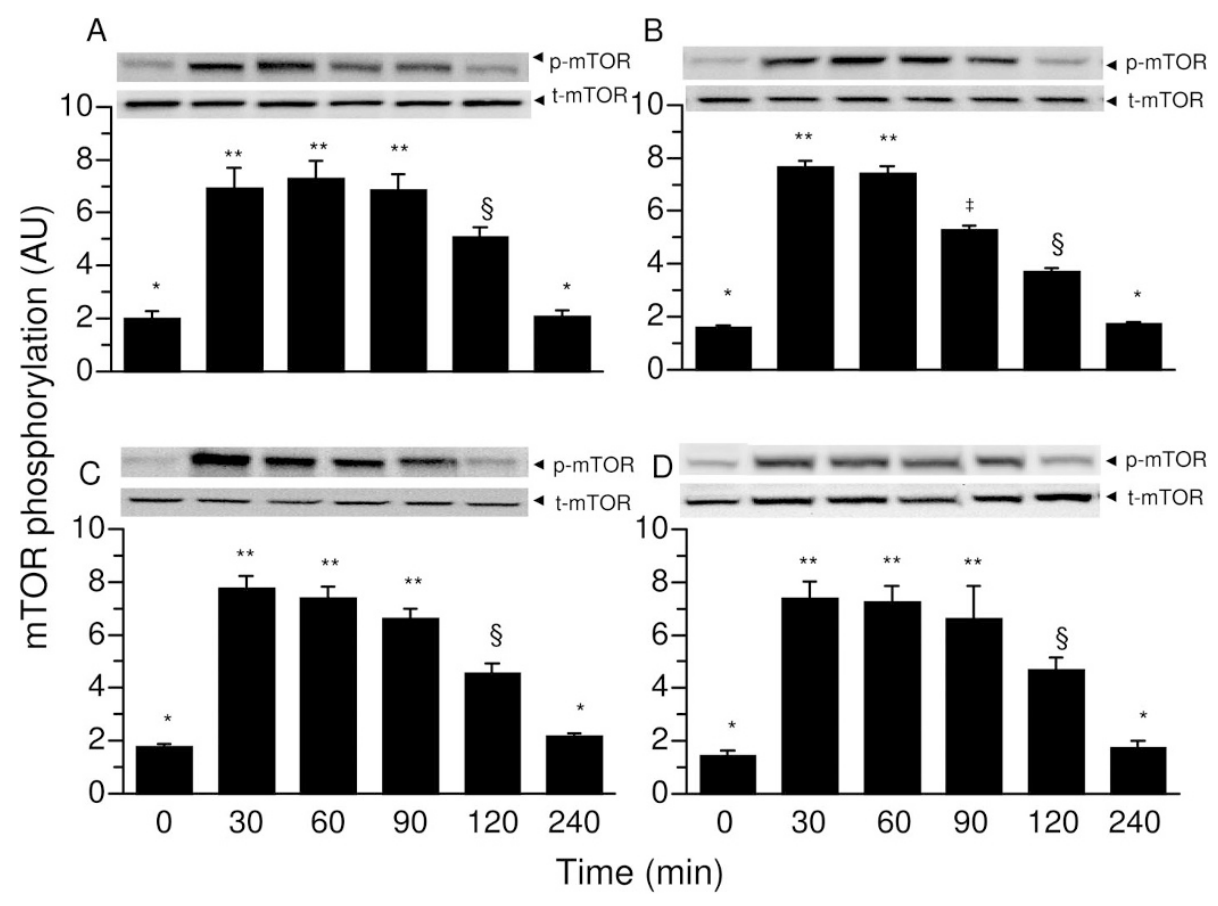

Figure 3. Time course of the changes in mTOR phosphorylation in gastrocnemius $(A)$, masseter $(B)$, soleus $(C)$, and left heart $(D)$ muscles of neonatal pigs after a meal. Values are means \pm SEM, $n=6$. Results were corrected for total protein. $\mathrm{AU}=$ arbitrary units. ANOVA showed a treatment effect $(p<0.01)$ for all tissues. Means without a common symbol differ, $p<0.05$. min in the jejunum and pancreas (Table 4; $p<0.05$ ), and returned to baseline by $240 \mathrm{~min}$.

rpS4 and rpS8 mRNA in polysomes in liver. The proportion of rpS4 and rpS8 mRNAs in liver polysomes increased at $30 \mathrm{~min}$
(Fig. 5; $p<0.05$ ) was sustained for 120 min after a meal but returned to baseline by $240 \mathrm{~min}$. The distribution of ODC, a negative control for regulation of the terminal oligopyrimidine (TOP) mRNA in polysomes, was unchanged by feeding. 
Table 4. Time course of the changes in the activation of various signaling proteins involved in translation in visceral tissues of neonatal pigs after a meal*

\begin{tabular}{|c|c|c|c|c|c|c|c|}
\hline & \multicolumn{6}{|c|}{ Time (min) } & \multirow[b]{2}{*}{$p$} \\
\hline & 0 & 30 & 60 & 90 & 120 & 240 & \\
\hline \multicolumn{8}{|l|}{ Liver } \\
\hline TSC2 on $\mathrm{Thr}^{1462}(\mathrm{AU})$ & $0.10 \pm 0.01 \dagger$ & $1.04 \pm 0.13 \neq$ & $0.90 \pm 0.11 \neq$ & $0.77 \pm 0.11 \S$ & $0.50 \pm 0.08 \|$ & $0.14 \pm 0.03 \dagger$ & $<0.05$ \\
\hline PRAS40 on $\mathrm{Thr}^{246}$ (AU) & $0.08 \pm 0.02 \dagger$ & $1.08 \pm 0.12 \div$ & $0.91 \pm 0.09 \ddagger$ & $0.68 \pm 0.12 \S$ & $0.40 \pm 0.06 \|$ & $0.10 \pm 0.02 \dagger$ & $<0.05$ \\
\hline RagB-mTOR (AU) & $0.72 \pm 0.07$ & $0.69 \pm 0.14$ & $0.67 \pm 0.09$ & $0.76 \pm 0.11$ & $0.64 \pm 0.09$ & $0.65 \pm 0.05$ & NS \\
\hline S6K1 on $\mathrm{Thr}^{398}$ (AU) & $0.07 \pm 0.01 \dagger$ & $0.47 \pm 0.09 \ddagger$ & $0.34 \pm 0.06 \neq$ & $0.36 \pm 0.07 \ddagger$ & $0.16 \pm 0.06 \|$ & $0.04 \pm 0.02 \dagger$ & $<0.05$ \\
\hline \multicolumn{8}{|l|}{ Jejunum } \\
\hline AMPK on $\mathrm{Thr}^{172}(\mathrm{AU})$ & $1.12 \pm 0.26$ & $0.96 \pm 0.16$ & $1.14 \pm 0.19$ & $1.38 \pm 0.21$ & $1.15 \pm 0.21$ & $1.01 \pm 0.23$ & NS \\
\hline TSC2 on $\operatorname{Thr}^{1462}(\mathrm{AU})$ & $0.43 \pm 0.09 \dagger$ & $6.41 \pm 0.93 \ddagger$ & $6.43 \pm 1.03+$ & $4.37 \pm 0.54 \S$ & $2.24 \pm 0.30 \|$ & $0.56 \pm 0.07 \dagger$ & $<0.05$ \\
\hline PRAS40 on $\mathrm{Thr}^{246}(\mathrm{AU})$ & $0.50 \pm 0.03 \dagger$ & $6.53 \pm 0.86 \neq$ & $5.81 \pm 0.66 \ddagger$ & $3.98 \pm 0.48 \S$ & $2.66 \pm 0.28 \|$ & $0.57 \pm 0.07 \dagger$ & $<0.05$ \\
\hline RagB-mTOR (AU) & $0.55 \pm 0.09$ & $0.70 \pm 0.10$ & $0.51 \pm 0.04$ & $0.56 \pm 0.09$ & $0.52 \pm 0.06$ & $0.53 \pm 0.06$ & NS \\
\hline S6K1 on $\mathrm{Thr}^{398}(\mathrm{AU})$ & $0.33 \pm 0.09 \dagger$ & $0.69 \pm 0.13 \neq$ & $0.82 \pm 0.11$ † & $0.76 \pm 0.10 \ddagger$ & $0.48 \pm 0.06 \|$ & $0.29 \pm 0.10 \dagger$ & $<0.05$ \\
\hline RagB-mTOR (AU) & $0.38 \pm 0.06$ & $0.45 \pm 0.07$ & $0.39 \pm 0.05$ & $0.40 \pm 0.04$ & $0.44 \pm 0.06$ & $0.41 \pm 0.04$ & NS \\
\hline S6K1 on $\mathrm{Thr}^{398}$ (AU) & $0.15 \pm 0.04 \dagger$ & $2.22 \pm 0.37 \ddagger$ & $2.00 \pm 0.42 末$ & $1.24 \pm 0.24 \|$ & $1.17 \pm 0.43 \|$ & $0.13 \pm 0.03 \dagger$ & $<0.05$ \\
\hline 4E-BP1 on $\mathrm{Thr}^{70}(\mathrm{AU})$ & $0.18 \pm 0.03 \dagger$ & $1.19 \pm 0.22 \ddagger$ & $1.25 \pm 0.15$ & $0.65 \pm 0.10 \|$ & $0.48 \pm 0.10 \|$ & $0.16 \pm 0.02 \dagger$ & $<0.05$ \\
\hline \multicolumn{8}{|l|}{ Kidney } \\
\hline AMPK on $\operatorname{Thr}^{172}$ (AU) & $0.52 \pm 0.06$ & $0.55 \pm 0.07$ & $0.50 \pm 0.06$ & $0.46 \pm 0.04$ & $0.48 \pm 0.11$ & $0.48 \pm 0.07$ & NS \\
\hline TSC2 on $\mathrm{Thr}^{1462}(\mathrm{AU})$ & $0.05 \pm 0.01 \dagger$ & $0.55 \pm 0.06 \neq$ & $0.58 \pm 0.10+$ & $0.42 \pm 0.10 \S \|$ & $0.33 \pm 0.04 \|$ & $0.06 \pm 0.01 \dagger$ & $<0.05$ \\
\hline PRAS40 on $\mathrm{Thr}^{246}$ (AU) & $0.11 \pm 0.02 \dagger$ & $1.32 \pm 0.10 \ddagger$ & $1.25 \pm 0.07 \ddagger$ & $0.99 \pm 0.15 \S \|$ & $0.58 \pm 0.06 \|$ & $0.15 \pm 0.03 \dagger$ & $<0.05$ \\
\hline RagB-mTOR (AU) & $0.61 \pm 0.10$ & $0.71 \pm 0.07$ & $0.57 \pm 0.12$ & $0.58 \pm 0.10$ & $0.62 \pm 0.05$ & $0.60 \pm 0.10$ & NS \\
\hline S6K1 on $\mathrm{Thr}^{398}(\mathrm{AU})$ & $0.13 \pm 0.03 \dagger$ & $2.79 \pm 0.48 \ddagger$ & $2.36 \pm 0.32 \ddagger$ & $1.53 \pm 0.23 \S$ & $1.05 \pm 0.15 \|$ & $0.15 \pm 0.04 \dagger$ & $<0.05$ \\
\hline 4E-BP1 on $\mathrm{Thr}^{70}(\mathrm{AU})$ & $0.22 \pm 0.05 \dagger$ & $1.74 \pm 0.17 \ddagger$ & $1.41 \pm 0.27 \ddagger$ & $1.13 \pm 0.16 \S$ & $0.75 \pm 0.13 \|$ & $0.28 \pm 0.07 \dagger$ & $<0.05$ \\
\hline
\end{tabular}

$*$ Values are means $\pm \mathrm{SEM}, n=6$. Means in a row with superscripts without a common symbol differ, $p<0.05$.

$\mathrm{AU}$, arbitrary units.

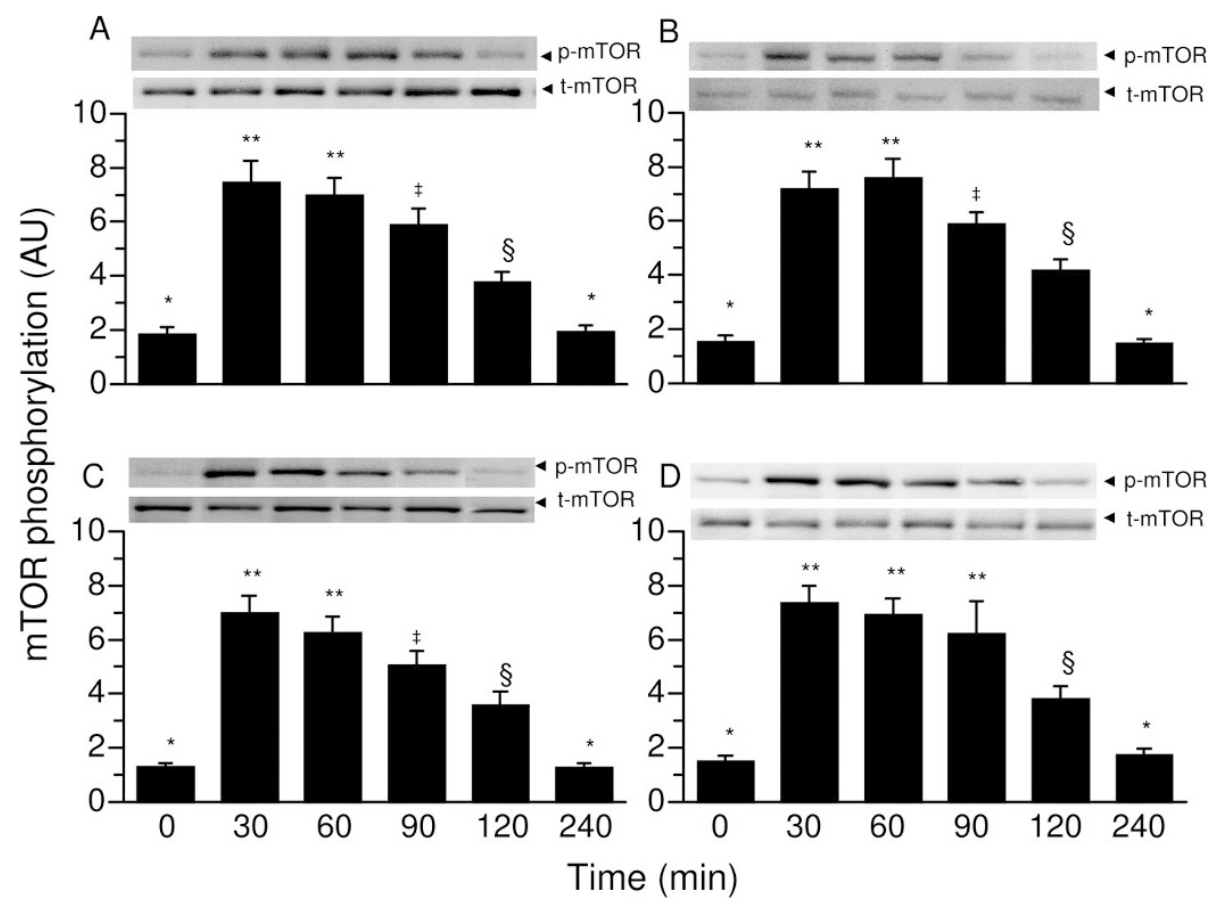

Figure 4. Time course of the changes in mTOR phosphorylation in liver $(A)$, jejunum $(B)$, pancreas $(C)$, and kidney $(D)$ of neonatal pigs after a meal. Values are means $\pm \operatorname{SEM}, n=$ 6. Results were corrected for total protein. $\mathrm{AU}=$ arbitrary units. ANOVA showed a treatment effect $(p<0.01)$ for all tissues. Means without a common symbol differ, $p<0.05$.

\section{DISCUSSION}

Previous investigations in newborn animals have shown that PS in skeletal muscle is stimulated by feeding $(7-9,24)$. However, most of the studies have examined the response at one time point (7), and have not evaluated the time course of the changes in PS in different tissues during the dynamic postabsorptive period. The current study shows that in muscle, the increase in PS after a bolus meal is fiber type dependent and 


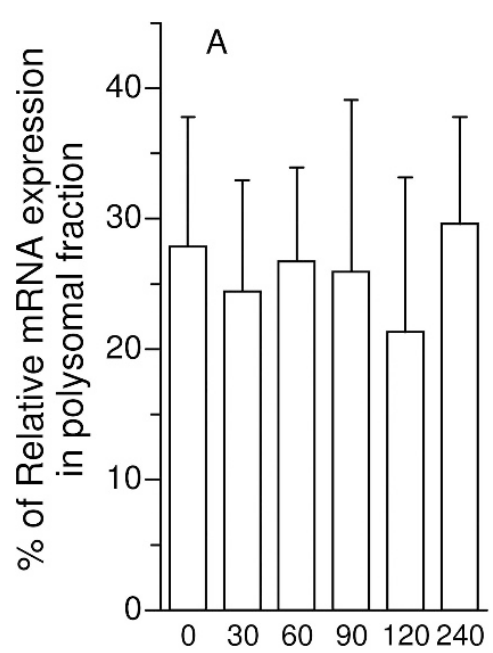

B

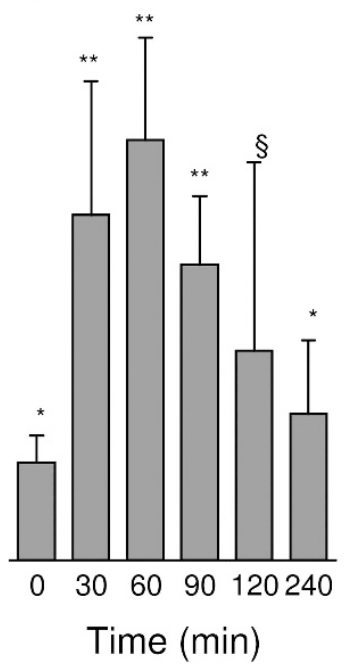

C

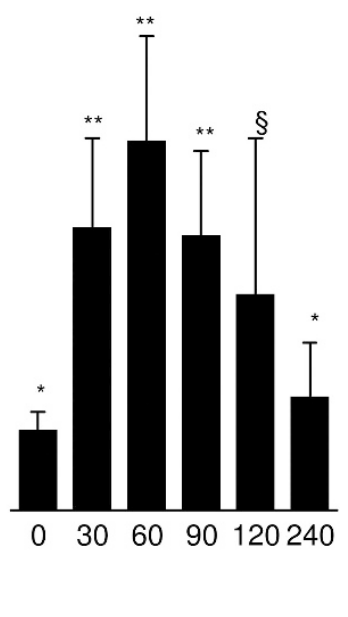

Figure 5. Proportion of ODC $(A)$, rp S4 $(B)$, and rp $\mathrm{S} 8(C)$ mRNAs in liver polysomes of neonatal pigs after a meal. Values are means \pm SEM, $n=6$. Results were normalized to GADPH. ANOVA showed a treatment effect $(p<0.05)$. Means without a common symbol differ, $p<0.05$. that the change in PS after a meal differed among visceral tissues. In addition, we demonstrated that gastric bolus feeding stimulated mTORC1 signaling in all muscles and viscera examined, but this increase in mTORC1 activation did not necessarily render an increase in PS rates in all tissues.

Postprandial stimulation of muscle PS. Our previous studies demonstrated that circulating insulin, AA, and glucose concentrations are elevated in neonatal pigs after a meal $(7,19)$, and that insulin and AA independently stimulate PS in skeletal muscle (11). Recently, we showed that after a bolus meal, PS in the longissimus dorsi, a muscle of primarily fast-twitch glycolytic fibers, reached maximal levels within 30 min of feeding, remained elevated for $120 \mathrm{~min}$, and closely mirrored the changes in circulating AA concentrations (19). The data also suggested that maximal rates of PS in the longissimus dorsi can be achieved at insulin levels less than the peak achieved after eating, at least in the presence of fed AA levels (19), consistent with results from our pancreaticsubstrate clamp studies $(21,25)$.

In the current study, we found that a bolus meal increased PS from 30 to $90 \mathrm{~min}$ in the fast-twitch glycolytic gastrocnemius muscle. However, PS increased for only $60 \mathrm{~min}$ in the masseter, a muscle of mixed fiber type, and did not respond to a meal in muscles of oxidative metabolism, such as soleus and heart. These findings support the hypothesis that muscles containing primarily fast-twitch glycolytic fibers are highly responsive to feeding and this is mediated by the increase in circulating AA, insulin, or both after a bolus meal. In neonatal pigs, glycolytic muscles account for a major component of mass deposition during growth (7). The unique responsiveness of PS in fast-twitch muscles, compared with other muscle types, to the postprandial state likely allows enhanced nutrient utilization to translate into higher protein deposition rates in neonates.

mTORC1 activation in muscle after a meal. Our previous studies revealed that feeding is effective in stimulating PS in skeletal muscle of neonates through activation of signaling components upstream and downstream of mTORC1 that lead to mRNA translation $(12,26)$. Of the upstream regulators of
mTORC1, it has been proposed that AA may act by inhibiting a negative regulator, TSC2. Phosphorylation of $\mathrm{Thr}^{1462}$ on TSC2 inhibits its Rheb-GTPase activity, thereby relieving inhibition of mTOR (17). Contrary to other studies (27), we found that a bolus meal enhanced TSC2 phosphorylation at 30 min, returning to baseline at $240 \mathrm{~min}$ in all muscles, probably mediated by activation of protein kinase $\mathrm{B}$ (PKB). Activation of RagB GTPase, also a regulator of mTORC1 (16), was not altered after a bolus meal in any muscle. Phosphorylation of AMPK, an energy sensor that activates TSC2 (17), was unaltered by feeding in muscles, suggesting that AMPK does not activate mTOR when sufficient energy and macronutrients are provided. Previously, we showed that AMPK is not altered by food deprivation or feeding in neonatal pigs, suggesting that AMPK is not a regulator of mTOR during the feeding/fasting cycle (23). The interaction of PRAS40 with mTORC1 inhibits the activity of mTORC1. Phosphorylation of PRAS40 by PKB and mTORC1 disrupts the binding between mTORC1 and PRAS40, and relieves the inhibitory constraint of PRAS40 on mTORC1 activity, allowing phosphorylation of S6K1 and 4EBP1 (15). In our study, we found an increase in mTORC1, PRAS40, 4EBP1, and S6K1 phosphorylation in gastrocnemius and masseter that peaked at 30 min postfeeding and paralleled the increase in PS. However, in soleus and left heart, mTORC1, PRAS40, 4EBP1, and S6K1 also were activated, but this was not associated with an increase in PS. Therefore, mTORC1 activation does not necessarily translate into a significant increase in PS rates in muscles of oxidative metabolism after a single meal, although, it may up-regulate the translation of a subset of mRNAs, as reported previously in rodents (28). Another explanation for this discrepancy could be that the activation of other signaling pathways, in addition to the mTOR pathway, may be needed to fully support the process of translation of mRNA into protein in these tissues.

Differential effects of a meal on visceral PS. Previous studies in neonatal pigs showed that liver PS increases in response to a rise in AA but not insulin (10,21). Our current study showed a significant increase in PS in liver 30 min after 
a meal that was sustained for at least $90 \mathrm{~min}$, consistent with the maximum increase in circulating BCAA after the meal commenced. These results are consistent with our previous pancreatic-substrate clamps studies $(10,18,21)$, which demonstrated that neonatal liver is highly sensitive to AA and highlight the importance of protein in the diet of the neonate in stimulating protein deposition.

The jejunum also is of major importance to whole body protein turnover (29). In our study, jejunal PS increased 30 min postfeeding and returned to baseline rates by $90 \mathrm{~min}$ postfeeding. Previous studies have shown that one-third of the dietary intake of EAA is consumed in first-pass metabolism by the intestine (30). The higher metabolic demands and firstpass metabolism may limit the ability of the intestine to sustain the postprandrial increase in PS.

Pancreatic-substrate clamp studies performed in our laboratory previously showed that AA stimulate PS in the pancreas (10); however, in that study, PS was not measured over time. In the current study, PS in the pancreas increased 30 min after feeding and returned to baseline levels by $60 \mathrm{~min}$. A possible explanation for the apparent blunting of the effect of feeding on PS is that isotopically labeled pancreatic protein was secreted and could not be detected.

Our previous studies demonstrated that infusion of AA alone, but not insulin alone, to reproduce fed levels, stimulated PS in kidney of neonatal pigs (25). In the current study, we found that a bolus meal failed to increase PS in the kidney. Whether differences in the results of our current and previous studies are because of differences in AA availability or other factors is unknown.

Effects of a meal on mTORC1 signaling in visceral tissues. In the liver and other visceral tissues examined, phosphorylation of TSC2 was significantly increased 30 min after a meal, returning to baseline at $240 \mathrm{~min}$. TSC2 phosphorylation leads to inhibition of GTP and activation of mTORC1 leading to translation initiation and PS (17). RagB GTPase and AMPK activation were unaltered by feeding in all viscera.

We have demonstrated that nutrient intake, particularly that of AA, is the primary stimulus for liver PS, and this response is mediated by an enhanced activation of the mTORC1 signaling pathway. The rp are principal players in promoting growth and contain specific regulatory elements that control their translational efficiency (31). In our study, we found S4 and S8 mRNA in polysomes increased 30 min postfeeding, which was maintained for at least $120 \mathrm{~min}$, and paralleled the increase in mTORC1, PRAS40, S6K1, and 4EBP1 phosphorylation, suggesting rapid movement of hepatic rp mRNAs into polysomes. This rapid redistribution along with the rapid activation of mTORC1 may contribute to an increase in ribosomal biogenesis and thus protein synthetic capacity in liver in response to feeding, leading to an increase in global rates of PS, and allowing the synthesis of visceral proteins.

In the jejunum, pancreas, and kidney, feeding a bolus meal increased phosphorylation of mTORC1, PRAS40, S6K1 and 4EBP1, suggesting mTORC1-dependent translation was activated. These findings in the jejunum and pancreas were consistent with the feeding-induced stimulation of pancreatic and jejunal PS in the current study, although the increase in
mTORC1, PRAS40, S6K1, and 4EBP1 phosphorylation in these tissues was more sustained than that for PS. However, we could not detect an increase in PS in the kidney despite the activation of these initiation factors. The results suggest that mTORC1-independent processes likely account for the discrepancies between changes in signaling through mTORC1 and PS.

Summary. The results of the present study suggest that feeding stimulates mTORC1 signaling in muscle and viscera, but the activation of this signaling pathway alone does not necessarily translate into equivalent changes in PS in all tissues and even among muscles that differ in their fiber metabolic and contractile properties. These findings provide additional insights into the processes involved in the stimulation of PS in different tissues after a bolus meal.

Acknowledgments. We thank Rosemarie Almonaci and Sharon Rannels for technical assistance, Jerome Stubblefield and Rickey Bryant for animal care, E. O'Brian Smith for statistical assistance, Adam Gillum for graphics, and Linda Weiser for secretarial assistance.

\section{REFERENCES}

1. Denne SC, Kalhan SC 1987 Leucine metabolism in human newborns. Am J Physiol 253:E608-E615

2. Denne SC, Rossi EM, Kalhan SC 1991 Leucine kinetics during feeding in normal newborns. Pediatr Res 30:23-27

3. Ehrenkranz RA 2007 Early, aggressive nutritional management for very low birth weight infants: what is the evidence? Semin Perinatol 31:48-55

4. Saigal S, Stoskopf BL, Streiner DL, Burrows E 2001 Physical growth and current health status of infants who were of extremely low birth weight and controls at adolescence. Pediatrics 108:407-415

5. Stephens BE, Vohr BR 2009 Neurodevelopmental outcome of the premature infant. Pediatr Clin North Am 56:631-646

6. Neubauer AP, Voss W, Kattner E 2008 Outcome of extremely low birth weight survivors at school age: the influence of perinatal parameters on neurodevelopment. Eur J Pediatr 167:87-95

7. Davis TA, Burrin DG, Fiorotto ML, Nguyen HV 1996 Protein synthesis in skeletal muscle and jejunum is more responsive to feeding in 7-than in 26-day-old pigs. Am J Physiol 270:E802-E809

8. Davis TA, Fiorotto ML, Nguyen HV, Reeds PJ 1993 Enhanced response of muscle protein synthesis and plasma insulin to food intake in suckled rats. Am J Physiol 265:R334-R340

9. Davis TA, Fiorotto ML 2009 Regulation of muscle growth in neonates. Curr Opin Clin Nutr Metab Care 12:78-85

10. Suryawan A, O'Connor PM, Bush JA, Nguyen HV, Davis TA 2009 Differential regulation of protein synthesis by amino acids and insulin in peripheral and visceral tissues of neonatal pigs. Amino Acids 37:97-104

11. O'Connor PM, Bush JA, Suryawan A, Nguyen HV, Davis TA 2003 Insulin and amino acids independently stimulate skeletal muscle protein synthesis in neonatal pigs. Am J Physiol Endocrinol Metab 284:E110-E119

12. Suryawan A, O'Connor PM, Kimball SR, Bush JA, Nguyen HV, Jefferson LS, Davis TA 2004 Amino acids do not alter the insulin-induced activation of the insulin signaling pathway in neonatal pigs. J Nutr 134:24-30

13. O'Connor PM, Kimball SR, Suryawan A, Bush JA, Nguyen HV, Jefferson LS, Davis TA 2003 Regulation of translation initiation by insulin and amino acids in skeletal muscle of neonatal pigs. Am J Physiol Endocrinol Metab 285:E40-E53

14. Suryawan A, Orellana RA, Nguyen HV, Jeyapalan AS, Fleming JR, Davis TA 2007 Activation by insulin and amino acids of signaling components leading to translation initiation in skeletal muscle of neonatal pigs is developmentally regulated. Am J Physiol Endocrinol Metab 293:E1597-E1605

15. Wang L, Harris TE, Roth RA, Lawrence JC Jr 2007 PRAS40 regulates mTORC1 kinase activity by functioning as a direct inhibitor of substrate binding. J Biol Chem 282:20036-20044

16. Kim E, Goraksha-Hicks P, Li L, Neufeld TP, Guan KL 2008 Regulation of TORC1 by Rag GTPases in nutrient response. Nat Cell Biol 10:935-945

17. Davis TA 2008 Insulin and amino acids are critical regulators of neonatal muscle growth. Nutr Today 43:143-149

18. O'Connor PM, Kimball SR, Suryawan A, Bush JA, Nguyen HV, Jefferson LS, Davis TA 2004 Regulation of neonatal liver protein synthesis by insulin and amino acids in pigs. Am J Physiol Endocrinol Metab 286:E994-E1003

19. Wilson FA, Suryawan A, Orellana RA, Kimball SR, Gazzaneo MC, Nguyen HV, Fiorotto ML, Davis TA 2009 Feeding rapidly stimulates protein synthesis in skeletal muscle of neonatal pigs by enhancing translation initiation. J Nutr 139:1873-1880 
20. Escobar J, Frank JW, Suryawan A, Nguyen HV, Kimball SR, Jefferson LS, Davis TA 2005 Physiological rise in plasma leucine stimulates muscle protein synthesis in neonatal pigs by enhancing translation initiation factor activation. Am J Physiol Endocrinol Metab 288:E914-E921

21. Davis TA, Fiorotto ML, Beckett PR, Burrin DG, Reeds PJ, Wray-Cahen D, Nguyen HV 2001 Differential effects of insulin on peripheral and visceral tissue protein synthesis in neonatal pigs. Am J Physiol Endocrinol Metab 280:E770-E779

22. Suryawan A, Davis TA 2010 The abundance and activation of mTORC1 regulators in skeletal muscle of neonatal pigs are modulated by insulin, amino acids and, age. J Appl Physiol 109:1448-1454

23. Wilson FA, Suryawan A, Gazzaneo MC, Orellana RA, Nguyen HV, Davis TA 2010 Stimulation of muscle protein synthesis by prolonged parenteral infusion of leucine is dependent on amino acid availability in neonatal pigs. J Nutr 140:264-270

24. Burrin DG, Davis TA, Ebner S, Schoknecht PA, Fiorotto ML, Reeds PJ, McAvoy S 1995 Nutrient-independent and nutrient-dependent factors stimulate protein synthesis in colostrum-fed newborn pigs. Pediatr Res 37:593-599

25. Davis TA, Fiorotto ML, Burrin DG, Reeds PJ, Nguyen HV, Beckett PR, Vann RC, O'Connor PM 2002 Stimulation of protein synthesis by both insulin and amino acids is unique to skeletal muscle in neonatal pigs. Am J Physiol Endocrinol Metab 282:E880-E890

26. Suryawan A, Escobar J, Frank JW, Nguyen HV, Davis TA 2006 Developmental regulation of the activation of signaling components leading to translation initiation in skeletal muscle of neonatal pigs. Am J Physiol Endocrinol Metab 291:E849-E859

27. Vary TC, Lynch CJ 2006 Meal feeding stimulates phosphorylation of multiple effector proteins regulating protein synthetic processes in rat hearts. J Nutr $136: 2284-2290$

28. Reiter AK, Anthony TJ, Anthony JC, Jefferson LS, Kimball SR 2004 The mTOR signaling pathway mediates control of ribosomal protein mRNA translation in rat liver. Int J Biochem Cell Biol 36:2169-2179

29. Stoll B, Burrin DG, Henry JF, Jahoor F, Reeds PJ 1999 Dietary and systemic phenylalanine utilization for mucosal and hepatic constitutive protein synthesis in pigs. Am J Physiol 276:G49-G57

30. Elango R, Pencharz PB, Ball RO 2002 The branched-chain amino acid requirement of parenterally fed neonatal piglets is less than the enteral requirement. J Nutr 132:3123-3129

31. Perry RP, Meyuhas O 1990 Translational control of ribosomal protein production in mammalian cells. Enzyme 44:83-92 